\title{
SOCIALIZAÇÃO \\ Onde a sociologia e as neurociências se encontram
}

\author{
Pedro Abrantes \\ Instituto Universitário de Lisboa (ISCTE-IUL), Centro de Investigação e Estudos de Sociologia \\ (CIES-IUL), Lisboa, Portugal
}

Resumo O artigo apresenta um diálogo entre perspetivas atuais, nos campos da sociologia e das neurociências, em torno dos processos de socialização, observando tensões e hiatos, mas também convergências e pistas para um desenvolvimento científico assente na cooperação interdisciplinar. Esta discussão centra-se em três domínios profundamente interligados: perceções e disposições; emoções e relações; consciência e reflexividade. Advoga-se que avanços recentes no campo das neurociências são valiosos para o desenvolvimento do conhecimento sociológico e vice-versa, nomeadamente numa questão central para ambos: o modo como desenvolvemos (e articulamos) disposições e um eu autobiográfico, a partir das experiências que vivemos.

Palavras-chave: habitus, disposições, emoções, consciência

Abstract The article provides a dialogue between current perspectives, in the fields of sociology and neurosciences, over the socialization processes, stressing tensions and gaps, but also some convergences and clues for a scientific development based on interdisciplinary cooperation. Such discussion is focused on three intertwined topics: perceptions and dispositions; emotions and relations; conscience and reflexivity. I argue that recent findings in neurosciences are valuable for an advance of the sociological knowledge (and vice versa), especially on a central question for both: the way people develop (and combine) dispositions and a biographical self, based on lived experiences.

Keywords habitus, dispositions, emotions, conscience.

Résumé Cet article présente un dialogue entre les approches actuelles, dans les champs de la sociologie et des neurosciences, autour des processus de socialisation, en observant les tensions et les cassures, mais aussi les convergences et les pistes pour un développement scientifique fondé sur la coopération interdisciplinaire. Ce débat est axé sur trois domaines profondément reliés entre eux: perceptions et dispositions; émotions et relations; conscience et réflexivité. L'article soutient que les avancées récentes dans le domaine des neurosciences sont précieuses pour le développement de la connaissance sociologique et vice-versa, surtout sur une question centrale pour les deux: la façon dont nous développons et (articulons) des dispositions et un moi autobiographique, à partir des expériences que nous vivons.

Mots-clés: habitus, dispositions, émotions, conscience.

Resumen Este artículo presenta un diálogo entre las perspectivas actuales en el campo de la sociología y las neurociencias en relación a los procesos de socialización observando tensiones y huecos, así como convergencias y pistas para un desarrollo científico sustentado en la cooperación interdisciplinar. Esta discusión se centra en tres apartados profundamente interligados: percepciones y disposiciones; emociones y relaciones; conciencia y reflexividad.

Se defiende que los avances recientes en el campo de las neurociencias son valiosos para el desarrollo del conocimiento sociológico y viceversa, particularmente en una cuestión central para ambos: el modo como desarrollamos (y articulamos) disposiciones y un yo autobiográfico a partir de las experiencias que vivimos.

Palabras-clave: habitus, disposiciones, emociones, conciencia.

A sociologia baseia-se no princípio de que nós, os seres humanos desenvolvemos linguagens, conhecimento, disposições, valores, papéis e identidades, em configurações 
culturais, estruturas sociais e quadros de interação específicos. Este princípio tem sido, aliás, reafirmado pelos inúmeros sociólogos que recusam, por um lado, a visão da sociedade enquanto organismo, sistema ou estrutura independente dos indivíduos que a compõem e, por outro, a perspetiva da sociedade enquanto um agregado de escolhas racionais dos indivíduos, a partir de cálculos universais (inatos?) de custo-benefício.

Assim sendo, não deixa de ser preocupante a pouca investigação e reflexão que temos produzido acerca dessa capacidade e, aliás, o modo como tendemos a contornar, nos nossos estudos, qualquer referência à natureza humana. Os próprios conceitos de ator ou agente social, fundamentais nas propostas de renovação científica e ética que pretendem colocar o ser humano, dotado de intencionalidade e subjetividade, no centro da análise sociológica, conservam tal ambiguidade, permitindo uma fuga às questões sobre a natureza, através da redução da sociologia ao estudo do modo como os indivíduos atuam (ou agem) em contextos sociais (como se existisse um ser humano independente dessa atuação ou agência).

Terry Leahi (2012) estudou um conjunto de manuais de sociologia com impacto internacional, publicados nas últimas duas décadas, e observou, precisamente, uma evasão dos temas relativos à natureza e uma crítica sistemática às explicações biológicas do comportamento humano, assente na ideia de que este resulta da socialização dos indivíduos. Segundo uma posição comum nestas obras, os seres humanos seriam radicalmente distintos dos restantes animais, pois os segundos seriam comandados por instintos, enquanto os primeiros seriam governados por - e, simultaneamente, coprodutores de - cultura(s). O mais interessante é que, numa leitura mais fina, o autor observa diversas referências implícitas a aspetos da natureza para explicar as ações em sociedade, como a necessidade de alimentação, de segurança, de integração, os impulsos agressivos, os sentimentos de medo, vergonha ou orgulho, a fuga a sanções e a agressões ou a busca de recompensas e de bem-estar. Como conclui, a natureza humana é o elefante invisível na sala da sociologia.

Num estudo sobre o modo como a socialização tem sido abordada em 16 revistas internacionais de referência, no campo sociológico, pude apurar que, não constituindo um tema central na agenda da investigação, a socialização surge como fator explicativo de um conjunto diversificado de fenómenos, como a participação política e cívica, a etnicidade e o desvio, a religião e os valores, as estruturas familiares e a identidade de género, o percurso educativo e a integração laboral, as histórias de vida e as memórias coletivas, a reprodução e a mobilidade social. ${ }^{1} \mathrm{Tal}$ como se aprofundou anteriormente (Abrantes, 2011), entendemos a socialização

1 O período analisado foi de 1991 a 2012 e as revistas consideradas foram: Acta Sociologica, American Journal of Sociology, American Sociological Review, Annual Review of Sociology, Current Sociology, European Journal of Social Theory, European Sociological Review, International Sociology, Journal of Sociology, Social Forces, Sociological Perspectives, Sociological Quarterly, Sociological Research Online, Sociological Review, Sociological Spectrum e Sociology. O principal critério para a construção desta amostra de artigos foi o facto de a palavra "socialização" surgir no título, nas palavras-chave ou no resumo. Foram identificados e analisados os 75 artigos nos quais a socialização constitui um dos temas centrais do trabalho, o que corresponde a cerca de $1 \%$ do universo dos artigos publicados nestas revistas naquele período. 
como o processo através do qual os indivíduos, ao longo da vida, participam na vida e, simultaneamente, incorporam um conjunto de referências que potenciam essa participação, incluindo linguagens, conhecimentos, crenças, valores, disposições, etc.

Uma observação dos quadros teóricos destes estudos não deixa de revelar uma significativa fragmentação das referências e, em muitos casos, uma "subteorização" do conceito de socialização. Obras fundamentais no ensino da sociologia, tais como as de Durkheim (1968 [1922]), Parsons (1968 [1951]) ou Berger e Luckmann (1998 [1966]), estão praticamente ausentes dos artigos analisados, sendo Pierre Bourdieu o que recolhe um maior número de referências sobre o tema autor que curiosamente não produziu teoria sobre a socialização como tal. Por seu lado, existe uma utilização frequente de referências de outros campos disciplinares, com particular destaque para a teoria da aprendizagem social de Albert Bandura (1977) que, sendo uma perspetiva consagrada na psicologia, assenta na ideia de que o comportamento e a cognição se desenvolvem, fundamentalmente, em resultado de estímulos, recompensas e reforços. Será este o elefante que queremos?

Entretanto, alguns sociólogos têm vindo a desenvolver notavelmente o conceito de socialização (Lahire, 2002 e 2005; Dubar, 2005; Darmon, 2007), sendo já referências importantes para alguns dos trabalhos recenseados. Estas teorizações, ora tecem duras críticas às pseudoexplicações do social provenientes da genética, da sociobiologia ou das "ciências cognitivas", ora recuperam autores clássicos da psicologia, sobretudo Freud e Piaget, com os quais, aliás, já haviam estabelecido um diálogo, mais ou menos explícito, as referidas obras de Durkheim, Parsons ou Berger e Luckmann. Se é certo que Freud e Piaget produziram contributos de uma riqueza inesgotável, este debate não dispensa uma atualização permanente, de parte a parte. Neste sentido, será importante reconhecer que, nas últimas décadas, se registaram enormes avanços no conhecimento sobre o funcionamento da mente humana, nomeadamente no campo das neurociências. Muitos destes estudos utilizam hoje conceitos como disposição, identidade ou eu (self), que são centrais na nossa disciplina, e inclusive têm providenciado à opinião pública explicações para diversos fenómenos sociais.

O impacto público destas démarches - que têm descurado, por seu lado, o grande volume de trabalho sociológico, elaborando explicações do social pelo biológico - comporta um sério risco de subalternização da sociologia, sobretudo nos domínios das ciências cognitivas e educacionais, mas não só, bem como de "tecnologização" da investigação e naturalização dos processos sociais - incluindo uma negligência acerca da diversidade, da dominação e da exclusão - apoiados por poderosos interesses políticos e económicos (Lahire, 2002; Pickersgill, 2013). É fundamental, portanto, reafirmar em que medida essas disposições, identidades e consciências são construídas em quadros culturais, estruturais e interacionais específicos, para utilizar a terminologia de António Firmino da Costa (1999).

Porém, em vez de generalizações a priori, a denúncia destas incursões ilegítimas pode ir a par de um diálogo interdisciplinar exigente e construtivo, proveitoso para o desenvolvimento de ambas as disciplinas e para o avanço do conhecimento científico, em geral. Neste artigo, na senda da proposta de Dores (2005) e dentro da 
linha que tenho vindo a desenvolver em estudos anteriores (Abrantes, 2011 e 2013), pretendo contribuir para este diálogo, discutindo alguns resultados de investigações do campo das neurociências que podem fortalecer a teoria sociológica acerca dos processos de socialização e, em sentido contrário, alguns avanços recentes do conhecimento sociológico que podem enriquecer a pesquisa sobre os processos mentais de aprendizagem. Não sendo precisamente sinónimos, os estudos recentes em ambos os domínios põem a nu as amplas áreas de convergência entre processos de socialização e de aprendizagem, assim como a utilidade de estabelecer uma ponte entre as investigações em ambos os domínios.

\section{Perceções e disposições}

Pesquisas recentes em neurociências têm mostrado que, longe de ser apreendida de forma imediata ou de ser determinada pela genética, a perceção que temos do nosso interior e, sobretudo, do mundo exterior é fortemente condicionada pelas nossas experiências passadas, devido à notável plasticidade do cérebro. A este propósito, as nossas capacidades percetivas, apesar de ocuparem uma grande parte do cérebro, são muito escassas à nascença e, assim permanecem, se não forem estimuladas desde uma idade precoce.

Mesmo na idade adulta, a nossa capacidade percetiva imediata permanece relativamente limitada e implica grandes gastos de energia. A perceção (visual, auditiva, etc.) que temos de uma dada situação depende, em grande medida, das experiências anteriores e daquilo que estamos motivados para alcançar. As cirurgias que têm restituído a visão a adultos cegos revelam, precisamente, as enormes dificuldades iniciais de interpretação e de processamento da informação visual, afetando a capacidade de identificar os objetos e o seu movimento, o que, em alguns casos, pode provocar danos cerebrais profundos (Sacks, 1996). Desde a infância, construímos, testamos e ajustamos continuamente suposições acerca da realidade, o que nos permite, a cada momento, focar-nos apenas nos aspetos que nos parecem fundamentais e que não correspondem aos mapas mentais previamente incorporados (Eagleman, 2012). Essas inferências não são apenas um conjunto de elementos memorizados de vivências anteriores, mas são, sobretudo, "narrativas" complexas sobre a nossa relação com o mundo, associadas a reações emocionais, juízos morais, nexos de causalidade e cálculos de probabilidade (Volpi, 2007).

Importa dizer que estes processos ocorrem a um nível inconsciente, orientados pela (e para a) prática, ativando um naipe alargado de perceções involuntárias, de memórias implícitas e de reações intuitivas. A prática permite assim inscrever um enorme volume de conhecimento no "espaço disposicional" - por vezes, designado também "memória maquinal" ou "sistema zombie", em livros de divulgação científica, conforme a metáfora preferida - e acioná-lo em situações análogas, com ganhos de velocidade reativa e poupança energética.

Se um sociólogo lê os parágrafos anteriores, será quase inevitável que venham à sua memória (explícita ou implícita) conhecidas teorizações relativas à "construção social da realidade" (Berger e Luckmann, 1998 [1966]), à "formação do 
habitus" (Bourdieu, 1987) ou às "configurações sociogenéticas" (Elias, 1994 [1989]), entre outras. Inclusive antes de as neurociências esmiuçarem os mecanismos mentais em que decorrem estes processos, o seu impacto na vida social já havia sido analisado. E o conhecimento sobre estes mecanismos neurais vem, aliás, interpelar as variantes mais intelectualistas e racionalistas da sociologia, que tendem a analisar a sociedade, respetivamente, como produto de construções subjetivas e discursivas ou de escolhas racionais e circunstanciais dos indivíduos.

Nesta linha, têm-se desenvolvido estudos sociológicos sobre disposições operatórias, morais, emocionais e estéticas, em grupos sociais específicos, como é o caso dos pugilistas (Wacquant, 2010) ou dos militares (Lande, 2007), bem como as limitações e inversões dos processos de socialização, no caso dos doentes afetados por doenças degenerativas, como doença de Alzheimer (Cicourel, 2013). Reconhecendo que a larga maioria das pessoas participa (e é socializada) hoje em diferentes contextos e comunidades, as mentes modernas tornam-se uma "teia de filiações sociomentais" (Zerubavel, 1997), o que nos converte em "atores plurais" (Lahire, 2002), alimentando simultaneamente os processos de individualização e reflexividade, devido aos nossos esforços permanentes (e nem sempre bem-sucedidos) de analogia e transferência.

Grande parte da investigação em neurociências foca-se em anomalias genéticas, doenças ou acidentes que transformam, geralmente limitando, mas em alguns casos também expandindo, as capacidades operatórias, de perceção e de memória (nas suas diferentes variantes). Será uma linha promissora de investigação explorar em que medida estes sistemas estão, na generalidade das pessoas, ancorados a estruturas e dinâmicas sociais. Ao assumir que a influência da sociedade (em particular da cultura) ocorre nos níveis de consciência mais sofisticados, muitos estudos neurológicos subestimam o facto de as experiências - que reconhecem ser fundamentais na construção das mentes humanas - não ocorrerem num "vazio social" ou por "livre iniciativa" do indivíduo, mas sim nos contextos sócio-históricos específicos em que estes atuam e em que decorreu a sua socialização (podendo uns e outros divergir notavelmente). E estes contextos são geradores, não apenas de recursos distintos e assimétricos, mas também de diferentes linguagens, modos de relacionamento e representações do mundo.

Note-se, porém, que já existem estudos sobre os efeitos neurológicos de práticas culturais. Por exemplo, Maguire e outros (2000) descobriram que os taxistas londrinos têm um hipocampo muito mais desenvolvido do que a média, sendo esta uma área chave para a memória de longo prazo, em particular no que concerne à navegação e memória espacial. A quantidade de estudos que mostram como atividades culturais alteram processos mentais e, inclusive, provocam transformações genéticas, a longo prazo, tem vindo a crescer (Laland, Odling-Smee e Miles, 2010).

Por seu lado, é importante para a sociologia considerar que a plasticidade do cérebro tem limites e que estes são variáveis, entre seres humanos e, sobretudo, ao longo da vida de cada um. Ou seja, as disposições formam-se no curso de vida, mas não em palestras ou ações de formação, dado que algumas delas implicam a estimulação desde uma idade precoce ou apenas se desenvolvem em "períodos críticos" do desenvolvimento do corpo, pelo menos para obter performances 
socialmente distinguidas (Skrzypczak, 1996; Li, 2009). Inclusive, a ausência de certos nutrientes e estímulos (ou a exposição em excesso a outros) - que sabemos associados a condições e estilos de vida -, em especial, durante a gravidez e a infância, podem provocar danos irreversíveis nos sistemas percetivos e de memória implícita (Handel, Cahill e Elkin, 2007).

Além disso, a socialização representa um encadeamento (e não apenas uma justaposição) de processos (Darmon, 2007). As noções de socialização primária e secundária representam uma primeira aproximação a este fenómeno, mas é evidente que precisamos de aprofundar a questão. Sabemos hoje, por exemplo, que as áreas neuronais responsáveis pela produção da consciência (o eu autobiográfico) são mais lentas a desenvolver-se, o que pode explicar alguns elementos específicos das culturas infantis e juvenis. E sabemos que, ao longo da vida, a rigidez do cérebro vai aumentando, o que promove processos de hysteresis (Bourdieu, 1987), enquanto a incidência de doenças degenerativas ("dessocializadoras") vai aumentando, o que não é independente dos contextos e estilos de vida.

Contudo, os sociólogos devem também ter presente que a investigação em neurociências não tem revelado a existência de qualquer sistema unificado ou coerente, gerador sistemático de práticas e representações, que funcione de forma independente da produção de significados (ou que controle essa produção). Embora este seja um campo em que muito está por descobrir, os avanços recentes parecem apontar, ao invés, para uma multiplicidade de sistemas disposicionais, em constante interação, mas com claras tensões entre si, sendo a sua harmonização um trabalho, sempre precário e a posteriori, realizado pelo eu (ver adiante o ponto "Consciência e reflexividade"). Assim, além da pluralidade das disposições que estão associadas aos diferentes contextos de vida e cuja transferência não é um dado adquirido (Lahire, 2002), torna-se igualmente importante que os sociólogos assumam que as próprias mentes são plurais, explorando, por exemplo, as diferenças, conflitos e negociações entre múltiplos processos mentais, configurados por diversas forças sociais. Por exemplo, estudar as relações entre as disposições rotinizadas e as elaborações conscientes, entre processos emocionais e racionais, entre desejos de curto e de longo prazo, entre memória quotidiana e memória dramática, entre lado direito e esquerdo do cérebro. A investigação das neurociências já tem produzido algum conhecimento nesta área (Eagleman, 2012), mas assumindo com frequência que, pelo menos, os primeiros elementos destes pares são biológicos (e simplificando frequentemente a dimensão social dos segundos). Se atendermos, por exemplo, ao modelo de "inteligências múltiplas" de Gardner (1995), temos sete distintas capacidades que se desenvolvem de forma autónoma, todas elas em interação com os quadros estruturais, culturais e relacionais específicos em que os indivíduos são socializados ao longo da vida. Os sociólogos podem efetivamente reconhecer as forças sociais que atuam na produção destes distintos mecanismos, bem como estudar os modos (socialmente construídos) de articulação (ou "negociação") entre eles. 


\section{Emoções e relações}

A investigação recente no campo das neurociências tem revelado a importância das emoções na regulação da vida humana, em questões fundamentais como a conservação e ativação das memórias (aprendizagem), os processos de tomadas de decisão ou a própria construção do eu. António Damásio (1995 e 2011) é uma das principais referências mundiais, a este respeito, tendo questionado o dualismo clássico entre mente e corpo, ao demonstrar o modo como as emoções, estando orientadas para a homeostase, constituem elementos fundamentais na regulação do corpo, mas também nos processos cognitivos e de tomada de decisão dos seres humanos. Em vez de reações instintivas e irracionais, as emoções permitem-nos, em pouco tempo, aceder à memória implícita, combinar inúmeras variáveis e tomar decisões eficazes para o nosso bem-estar pessoal (mesmo que não as consigamos explicar, senão por referência à intuição).

O autor português distingue emoções básicas (dor, prazer, medo, nojo, etc.) e emoções sociais (vergonha, orgulho, desprezo, etc.), atribuindo uma menor importância a estas últimas, como criação evolutiva recente e pouco profunda, em termos neurológicos. Diferencia também emoções e sentimentos, considerando que estes últimos são interpretações conscientes, culturalmente situadas, das reações emocionais. No entanto, Damásio (2011) reconhece que as emoções sociais são criadas nas mesmas regiões que as emoções básicas, envolvendo processos cerebrais profundos e intimamente associados à construção do $e$ u. Assim, uma emoção social como o desprezo, por exemplo, constitui uma apropriação social de uma repulsa biológica (o nojo).

$\mathrm{Na}$ linha de autores como Durkheim, Goffman ou Bourdieu, os avanços recentes no campo da sociologia das emoções têm colocado em causa este mapa conceptual, ao mostrar como os padrões culturais, as estruturas sociais e os quadros de interação têm um impacto profundo, não apenas nos sentimentos, mas também nos dispositivos e registos emocionais dos indivíduos, incluindo as emoções mais básicas. A diferença (e tensão) entre as emoções geradas, de forma espontânea, nomeadamente no âmbito das relações de poder, e a capacidade dos seres humanos de gerirem essas emoções, a partir de "guiões culturais" incorporados em processos de socialização (também eles profundamente assimétricos), constitui um dos temas em foco em muitos destes trabalhos (Turner e Stets, 2006; Handel, Cahill e Elkin, 2007).

Além disso, tal como nota Dores (2005), a ideia em voga nas neurociências de que os desenvolvimentos culturais derivam dos mecanismos biológicos de homeostase e seleção natural é controversa, pois parece não reconhecer que a vida social tem lógicas próprias e que não tendem, necessariamente, para o equilíbrio ou a preservação da espécie. Curiosamente, o neurocientista Eagleman (2012) percorre o caminho inverso - igualmente polémico - ao defender que a mente humana tem um conjunto de propriedades que habitualmente atribuímos às sociedades, como é o caso da existência de diversas forças que estabelecem relações de cooperação, concorrência, conflito e negociação entre si.

Todavia, como sociólogos, devemos ter em consideração que as emoções são elementos fundamentais na produção e ativação de memórias, na construção do eu e, por conseguinte, nos processos de socialização. 
Um dos mecanismos fundamentais é ativado numa região do cérebro composta pela amígdala e pelo hipocampo, responsável por explorar o mundo exterior e alertar-nos sempre que existem situações de perigo, gerando reações imediatas de grande intensidade emocional, expandindo momentaneamente as nossas capacidades percetivas e operativas. Além disso, estes "alertas" permitem conservar memórias de longo prazo e ativá-las sempre que nos deparamos com situações idênticas (Franks, 2006). Por seu lado, um desgaste prolongado das "hormonas do stress" causa perdas seletivas de memória (traumas).

O trabalho de Joan Ferrés i Prats (2008), ao contrastar os modelos de comunicação das escolas e dos media, foca a importância das emoções (quer positivas quer negativas) no estabelecimento de sintonias e, por conseguinte, na possibilidade de se produzirem (ou não) processos de aprendizagem (tanto voluntários como involuntários). Também o estudo das autobiografias dos participantes num programa de educação de adultos permitiu-nos explorar o modo como certas experiências dramáticas são recordadas, em detalhe, ao longo de toda a vida e marcam profundamente os processos de socialização (Abrantes, 2013). Outro exemplo de como as emoções podem estar na base de representações, crenças e práticas é fornecido por um estudo sociológico recente que mostra que a religiosidade dos indivíduos está fortemente correlacionada, não apenas com a sua socialização familiar, mas também com sentimentos de insegurança pessoal e societal (Ruiter e van Tubergen, 2009). O que acontece é que essa insegurança, mais do que uma disposição genética, está associada também à socialização dos indivíduos, em condições sociais, padrões culturais e quadros de interação específicos.

Este exemplo conduz-nos às relações de longa duração que estabelecemos uns com os outros e que podem adquirir uma enorme carga emocional muito intensa. Tal como nota Settersten Jr. (2002), os estudos sobre a socialização devem, por um lado, focar as relações afetivas quotidianas (familiares, de amigos ou de trabalho), no âmbito das quais construímos (e sintonizamos) as nossas formas de pensar, sentir e agir, seja por identificação seja por distinção, e, por outro lado, considerar que, pelo menos na idade adulta, estas relações podem adquirir formas bastante abstratas, como a pertença a uma geração, a uma profissão ou a uma nação. Meyer e Lobao (2003) fornecem evidência empírica deste fenómeno, ao mostrar como as atitudes políticas relativamente às transformações económicas são fortemente influenciadas pelos esposos/esposas. As autoras contestam, desta forma, o peso atribuído à socialização primária, na literatura sociológica, defendendo o conceito de "socialização mútua".

A este propósito, uma área relevante de investigação é aquela que se prende com o conhecimento sobre os "neurónios-espelho", responsáveis pela mimética, isto é, a capacidade de nos colocarmos na pele de outros, enquanto os observamos, sentindo aquilo que os outros estão a sentir, o que tem uma utilidade evidente: permite-nos cooperar uns com os outros, assim como prever se nos querem atacar (Damásio, 2011). A literatura, o teatro e o cinema, por exemplo, têm-se baseado nesta capacidade e alargado o seu campo de possibilidades, providenciando experiências significativas de socialização em contextos remotos (Volpi, 2007). Visto que a nossa mente consegue simular movimentos corporais e estados emocionais 
alheios, a interação entre pessoas e o próprio processo de socialização ocorrem a um nível mais profundo do que os processos conscientes de observação e de comunicação (Brown e Seligman, 2009).

É interessante colocar em diálogo estes avanços das neurociências com os estudos que têm vindo a explorar os substratos emocionais das relações de poder e, em particular, da estrutura de classes. Mesmo reconhecendo que a "consciência de classe" é hoje fraca, em muitos contextos sociais, os trabalhos de Diane Reay (2005) têm vindo a revelar um conjunto de emoções - tais como o ressentimento, a culpa, a vergonha, a retração, o medo, a confiança, a empatia, a inveja, a satisfação, a deferência, a arrogância, o desprezo, o orgulho, a raiva, o embaraço ou a pena - que são produzidos nas (e regulam as) relações de classe, desde a infância. A autora distingue então duas fações das classes médias, uma caracterizada pela satisfação e o desprezo, a outra pela culpa e a empatia, bem como dois perfis na classe trabalhadora, um pautado pelo ressentimento e o orgulho, o outro pela deferência e a vergonha. Por seu lado, segundo Andrew Sayer (2005), estas emoções estão intimamente associadas a julgamentos morais implícitos sobre aquilo que cada indivíduo é, deve ser, tem e merece. De forma semelhante, Turner e Stets (2006) assinalam como as emoções, nas relações humanas, estão fortemente articuladas com as noções de justiça acerca dos direitos e deveres atribuídos a cada um.

\section{Consciência e reflexividade}

A investigação em neurociências tem também produzido importantes avanços no estudo da consciência, mostrando que esta é um produto do cérebro e, especificamente, de uma combinação entre genes e experiências, ao longo da vida. Embora reconheçam que uma grande parte das operações mentais permanece inconsciente, o que, aliás, contribui para a sua eficácia, autores como Damásio (2011) ou Eagleman (2012) notam que a consciência significou um passo fundamental na evolução da espécie, permitindo-lhe enormes ganhos de regulação, adaptação e dominação, incluindo o desenvolvimento de estruturas simbólicas cada vez mais complexas e abstratas.

Segundo estes autores, a consciência é o maestro que permite coordenar os diversos circuitos disposicionais e imagéticos, construindo um conhecimento mais sofisticado e abstrato acerca do eu e do mundo exterior, com vantagens na interpretação das situações e na regulação das ações. Visto que, em cada momento, o volume de informação que conseguimos reter na consciência é limitado, as emoções produzem marcadores acerca dos elementos que são decisivos e com os quais as disposições não estão a conseguir lidar, nos quais, portanto, a consciência deve focar-se. Importa notar que a consciência não se forma numa região específica do cérebro, mas em circuitos neurais complexos que articulam diferentes regiões. Porém, existem efetivamente especificidades próprias na ativação da consciência, evidentes nos casos de acidentes e anomalias que inviabilizam a utilização de certas áreas, mas também nas diversas situações quotidianas, vividas por qualquer indivíduo, em que os sistemas disposicionais e conscientes não coincidem. 
Damásio (2011) caracteriza três etapas do desenvolvimento da consciência. Na base, encontra-se o proto-eu, composto por sentimentos primordiais acerca do próprio corpo (por exemplo, a consciência de ter fome). Num segundo momento, desenvolve-se o eu nuclear, enquanto um reconhecimento (uma narrativa coerente acerca) da relação imediata entre o corpo e o meio exterior (a consciência do aqui e agora). No terceiro momento, forma-se o eu autobiográfico, assente na capacidade de relacionar as experiências ocorridas ao longo da vida, através de uma coordenação e evocação das memórias de longo prazo. Um duplo processo de ajustamento está, permanentemente, em curso: o presente (o aqui e agora) é interpretado à luz do passado, mas o passado também é recriado à luz do presente (Sacks, 1996). Note-se que a memória e a consciência autobiográficas (a construção do eu) estão intimamente associadas ao desenvolvimento dos sistemas emocionais, mas também à criatividade e às competências linguísticas e sociais, como se tem observado nas pesquisas sobre o autismo.

Embora a investigação sobre este tema ainda se esteja a iniciar, alguns estudos que cruzam neurociências e antropologia têm mostrado uma variação significativa nos processos de formação do $e$, consoante o contexto cultural em que vivemos. Assim, Han e Northoff (2009) argumentam que o eu e o outro são representados, não através de processos mentais distintos, mas sim num continuum de self-relatedness. Ou seja, os processos mentais que ativamos, ao pensar em pessoas que consideramos próximas de nós, têm mais semelhanças com aqueles que ativamos quando pensamos em nós próprios do que quando pensamos em pessoas que consideramos estranhas.

A partir de algumas experiências, os autores confirmam que existem variações culturais importantes nos processos mentais de construção do eu e do outro. Assim, quando abordam um tema relativo à sua mãe, os chineses ativam uma zona do cérebro (MPFC) que os norte-americanos só ativam quando pensam em si próprios. Em termos comparativos, os segundos ativam mais áreas do cérebro quando veem fotos de si mesmos, mas ativam menos áreas quando observam imagens dos seus familiares. É interessante que, segundo estes autores, este "sentido de identificação", bem como o seu oposto "sentido de distinção", são experiências afetivas (culturalmente condicionadas) e que dão origem a um mapa interno de self-relatedness.

Mesmo sem considerar mudanças físicas no cérebro, vários neurologistas têm vindo a notar como a adoção de certos papéis sociais permite alterar as configurações neurais que coordenam os padrões motores (disposições), o que permite inclusive superar certos problemas mentais. É o caso, por exemplo, de um paciente de Oliver Sacks (1996), cujas manias e tiques compulsivos (síndrome de Tourette), que o afligiam frequentemente, se suspendiam no momento em que assumia a sua atividade profissional como cirurgião. Como conclui o autor, "o que aqui se observa é um ato fundamental de encarnação ou personificação, por meio do qual as aptidões, os sentimentos, a totalidade dos engramas neurais dum outro eu, depois de assumirem o controlo do cérebro, redefinem a pessoa e todo o seu sistema nervoso enquanto dura a representação" (1996: 133). Esta constatação permite-nos observar o efeito profundo da consciência, inclusive, sobre as disposições inconscientes dos indivíduos. 
Não devemos, pois, ser reticentes em utilizar o conceito de consciência, receando alguma incursão em mecanismos inatos ou espirituais, quando as neurociências têm revelado que se trata de um produto da mente e, simultaneamente, da sociedade em que esta se desenvolve. A este propósito, será útil convocar os trabalhos sobre a identidade, a reflexividade e a construção biográfica, desenvolvidos por autores como Anthony Giddens (1994), Beck e Beck-Gernsheim (2003) ou Margaret Archer (2007), entre outros, reconhecendo que constituem fenómenos muito mais antigos na história da Humanidade, mas que se desenvolveram notavelmente na modernidade, em estreita associação com um conjunto de "instituições abstratas" (a ciência, os media, o estado-providência, o mercado, a escola, etc.). As transformações em curso noutras regiões do mundo implicam estudarmos este tema, hoje, assumindo a existência de "modernidades múltiplas" (Eisenstadt, 2001).

Por seu lado, tal como a importância das disposições desafia as perspetivas sociológicas mais racionalistas, os estudos sobre a consciência não deixam de colocar em causa as teorias mais "disposicionalistas", em que as ações individuais são "orquestradas sem serem o produto da atividade organizadora de um maestro", nas palavras de Bourdieu (1987: 193). Sendo as disposições incorporadas, em grande medida de forma inconsciente, em diferentes contextos e etapas de vida, sem haver uma necessária coerência e transferência entre si (Lahire, 2002), existe efetivamente uma consciência (o tal maestro) que procura permanentemente (re)construir uma narrativa única e consistente, mesmo que provisória e precária, acerca do $e u$ e do mundo envolvente, a partir da evocação de memórias produzidas em diferentes experiências vividas, impondo uma certa ordem sobre a pluralidade disposicional.

No seu tratado sobre o processo de socialização, Muriel Darmon (2007) distingue precisamente dois mecanismos distintos, nem sempre coerentes: um ocorrendo ao nível do corpo, o outro ocorrendo ao nível da linguagem (ambos ocorrem no cérebro, mas em processos distintos). $O$ autor assume que a socialização, sendo fundamental para a constituição da consciência, inclui hoje uma dimensão de "trabalho sobre si", parcialmente orientado pela intencionalidade individual.

É neste ponto que será importante reequacionar a já conhecida crítica ao conceito de habitus, pela pouca importância atribuída à consciência e, em particular, à racionalidade (Casanova, 1995). Afastando-nos de noções naturalistas da racionalidade, importa, contudo, investigar o peso de certas operações mentais, assentes em princípios abstratos e universalistas (o que não significa universais), associados a princípios morais (aquilo que é correto, legítimo e eficaz) e incorporados através de processos de socialização específicos e prolongados no tempo (com destaque para os sistemas educativos e meios de comunicação social, mas não só), na forma como os indivíduos vivem, pensam e agem, nas sociedades contemporâneas (mesmo quando isso os prejudica ou oprime, objetivamente).

Contudo, a referida conceção de três distintos níveis na formação da consciência abre também espaço à discussão acerca de possíveis divergências e tensões entre eles. Como nota Sacks (1996), sendo a consciência autobiográfica constituída em forte associação com os mecanismos emocionais, há traumas e bloqueios psicológicos provocados pela incapacidade de integrar certas memórias ou perceções na 
restante narrativa autobiográfica. Daí que as pessoas possam tornar-se resistentes a aprender com certas experiências. Aliás, este é um dos princípios fundamentais da psicanálise, na sua busca por tornar conscientes as memórias que permanecem reprimidas, afetando os estados mentais, as perceções e os comportamentos dos indivíduos.

A este propósito, a par dos estudos mais circunscritos à formação de certas disposições, valores ou identidades, tem-se desenvolvido uma linh de estudos sobre a "socialização autobiográfica", consolidando a ideia de que a história de vida (incluindo a sua dimensão prospetiva) constitui um stock estável e duradouro de (auto)conhecimento, mesmo em períodos de grande transformação sócio-histórica, como foi o caso da transição para o capitalismo e para a democracia liberal, na Europa de Leste (Hoerning e Alheit, 1995; Kupferberg, 1998). Mas a relação entre socialização situacional e autobiográfica requer maior investigação, de preferência interdisciplinar. Na sua obra dedicada ao processo de socialização, Claude Dubar (2005) distingue precisamente a construção de uma "identidade relacional", baseada no aqui e agora (ou seja, variável consoante o momento e o contexto de vida), e uma "identidade autobiográfica", enquanto uma narrativa mais estável e que relaciona as diferentes etapas e contextos da vida individual, mas não explora, nem teórica nem empiricamente, as relações (e conflitos) entre elas.

\section{Notas conclusivas}

Ao longo do presente artigo, estabelecem-se algumas pontes entre a investigação recente em sociologia e em neurociências, em particular sobre os processos de socialização. Importa notar que este diálogo não nos permite estabelecer qualquer princípio comum que permita explicar o social pelo biológico (ou vice-versa). Desta forma, procura-se mostrar como um conhecimento recíproco atualizado é útil para o desenvolvimento de ambas as áreas, desde que se respeitem as especificidades teóricas e metodológicas de cada uma delas.

Um dos principais obstáculos a uma abordagem interdisciplinar encontra-se, precisamente, nas divergências metodológicas. Mesmo que seja possível construir um quadro teórico em que se articulem conceitos e resultados de investigação de ambas as áreas, os protocolos metodológicos considerados válidos, em cada uma delas, permanecem claramente diferenciados (Brown e Seligman, 2009). Ainda assim, a crescente importância, atribuída em ambos os campos às abordagens biográficas constitui uma base promissora para futuras aproximações entre os dois campos.

A estruturação do artigo em três domínios não pretende, obviamente, abarcar todas as questões em que esta relação entre neurociências e sociologia pode ser explorada. Além disso, devemos sublinhar que as disposições, as emoções e a consciência não são geradas em áreas bem delimitadas do cérebro e funcionam de forma profundamente interligada, na grande maioria das situações. Por seu lado, nenhum destes domínios é mais biológico ou mais social do que outros.

Contudo, procurámos ao longo do artigo mostrar que, em termos analíticos, existem vantagens em distinguir estes três domínios, no sentido em que efetivamente 
eles podem ativar circuitos neurais distintos, forças sociais diferentes e tipos de ação divergentes. Busquei, desta forma, contribuir para que, após o reconhecimento de que vivemos em sociedades plurais e de que somos, nós próprios, atores plurais, enquanto sociólogos, estudemos também as implicações de possuirmos mentes plurais.

\section{Referências bibliográficas}

Abrantes, Pedro (2011), "Para uma teoria da socialização", Sociologia - Revista da Faculdade de Letras da Universidade do Porto, 21, pp. 121-139.

Abrantes, Pedro (2013), “Opening the black box of socialization: emotions, practices and (biographical) identities", International Journal of Sociology and Anthropology, 5 (9), pp. 391-401.

Archer, Margaret S. (2007), Making Our Way through the World. Human Reflexivity and Social Mobility, Cambridge, Cambridge University Press.

Bandura, Albert (1977), Social Learning Theory, Englewood Cliffs, Prentice Hall.

Beck, Ulrich, e Elisabeth Beck-Gernsheim (2003), La Individualización. El Individualismo Institucionalizado y Sus Consecuencias Sociales y Políticas, Barcelona, Paidós.

Berger, Peter, e Thomas Luckmann (1998 [1966]), A Construção Social da Realidade. Tratado de Sociologia do Conhecimento, Petrópolis, Vozes.

Bourdieu, Pierre (1987), Esquisse d'Une Théorie de la Pratique, Genebra, Droz.

Brown, R. A., e R. Seligman (2009), "Anthropology and cultural neuroscience: creating productive intersections in parallel fields", em Joan Y. Chiao (org.), Cultural Neuroscience. Cultural Influences on Brain Function, Nova Iorque, Elsevier, pp. 31-42.

Casanova, José Luís (1995), “Uma avaliação conceptual do habitus", Sociologia, Problemas e Práticas, 18, pp. 45-68.

Cicourel, Aaron V. (2013), "Origin and demise of socio-cultural presentations of self from birth to death: caregiver 'scaffolding' practices necessary for guiding and sustaining communal social structure throughout the life cycle", Sociology, 47 (1), pp. 51-73.

Costa, António Firmino da (1999), Sociedade de Bairro. Dinâmicas Sociais da Identidade Cultural, Oeiras, Celta Editora.

Damásio, António (1995), O Erro de Descartes. Emoção, Razão e Cérebro Humano, Mem Martins, Publicações Europa-América.

Damásio, António (2011), O Livro da Consciência. A Construção do Cérebro Consciente, Lisboa, Temas e Debates.

Darmon, Muriel (2007), La Socialisation, Paris, Armand Colin.

Dores, António Pedro (2005), “Os erros de Damásio: homenagem a uma fonte de inspiração", Sociologia, Problemas e Práticas, 49, pp. 119-138.

Dubar, Claude (2005), A Socialização. Construção das Identidades Sociais e Profissionais, São Paulo, Martins Fontes.

Durkheim, Emile (1968 [1922]), Education et Sociologie, Paris, Presses Universitaires de France. Eagleman, David (2012), Incógnito. As Vidas Secretas do Cérebro Humano, Lisboa, Presença. Eisenstadt, Schmuel (2001), “Modernidades múltiplas”, Sociologia, Problemas e Práticas, 35, pp. 139-163. 
Elias, Norbert (1994 [1989]), Teoria Simbólica, Oeiras, Celta Editora.

Ferrés i Prats, Joan (2008), La Educación como Industria del Deseo. Un Nuevo Estilo Comunicativo, Barcelona, Gedisa.

Franks, David (2006), "The neuroscience of emotions", em Jonathan Turner e Jan Stets (orgs.), Handbook of the Sociology of Emotions, Nova Iorque, Springer US, pp. 38-62.

Gardner, Howard (1995), Inteligências Múltiplas. A Teoria na Prática, Porto Alegre, Artes Médicas.

Giddens, Anthony (1994), Modernidade e Identidade Pessoal, Oeiras, Celta Editora.

Han, Shihui, e Georg Northoff (2009), “Understanding the self: a cultural neuroscience approach", em Joan Y. Chiao (org.), Cultural Neuroscience. Cultural Influences on Brain Function, Nova Iorque, Elsevier, pp. 203-212.

Handel, Gerald, Spencer Cahill, e Frederik Elkin (2007), Children and Society. The Sociology of Children and Childhood Socialization, Los Angeles, Roxbury.

Hoerning Erika, e Peter Alheit (1995), “Biographical socialization”, Current Sociology, 43 (2), pp. 101-114.

Kupferberg, Feiwel (1998), “Transformation as biographical experience: personal destinies of East Berlin graduates before and after unification", Acta Sociologica, 41 (2-3), pp. 243-267.

Lahire, Bernard (2002), Homem Plural. Os Determinantes da Ação, Petrópolis, Vozes.

Lahire, Bernard (2005), L'Esprit Sociologique, Paris, La Découverte.

Laland, Kevin, John Odling-Smee, e Sean Miles (2010), “How culture shaped the human genome: bringing genetics and the human sciences together", Nature Reviews Genetics, 11, pp. 137-148.

Lande, Brian (2007), "Breathing like a soldier: culture incarnate", The Sociological Review, 55, pp. 95-108.

Leahi, Terry (2012), “The elephant in the room: human nature and the sociology textbooks", Current Sociology, 60 (6), pp. 806-823.

Li, Shu-Chen (2009), "Brain in macro experiential context: biocultural co-construction of lifespan neurocognitive development", em Joan Y. Chiao (org.), Cultural Neuroscience. Cultural Influences on Brain Function, Nova Iorque, Elsevier, pp. 17-29.

Maguire, Eleanor, e outros (2000), “Navigation-related structural change in the hippocampi of taxi drivers", Proceedings of the National Academy of Science, 97 (8), pp. 4398-4403.

Meyer, Katherine, e Linda Lobao (2003), "Household, gender, and political responses to economic downturn: extending theories of mobilization", The Sociological Quarterly, 44 (2), pp. 159-179.

Parsons, Talcott (1968 [1951]), La Estructura de la Acción Social, Madrid, Guadarrama.

Pickersgill, Martyn (2013), “The social life of the brain", Current Sociology, 61, pp. 322-340.

Reay, Diane (2005), "Beyond consciousness? The psychic landscape of social class", Sociology, 39 (5), pp. 911-928.

Ruiter, Stijn, e Frank van Tubergen (2009), “Religious attendance in cross-national perspective: a multilevel analysis of 60 countries", American Journal of Sociology, 115 (3), pp. 863-895.

Sacks, Oliver (1996), Um Antropólogo em Marte, Lisboa, Relógio D’Água. 
Sayer, Andrew (2005), The Moral Significance of Class, Cambridge, Cambridge University Press.

Settersten Jr., Richard (2002), “Socialization and the life course: new frontiers in theory and research", Advances in Life Course Research, 7, pp. 13-40.

Skrzypczak, Jean-François (1996), O Inato e o Adquirido. Desigualdades "Naturais", Desigualdades Sociais, Lisboa, Instituto Piaget.

Turner, Jonathan, e Jan Stets (2006), "Sociological theories of human emotions", Annual Review of Sociology, 32, pp. 25-52.

Volpi, Jorge (2007), Leer la Mente. El Cerebro y el Arte de la Ficción, Cidade do México, Alfaguara.

Wacquant, Loïc (2010), “L'habitus comme objet et méthode d'investigation”, Actes de la Recherche em Sciences Sociales, 184, pp. 108-121.

Zerubavel, Eviatar (1997), Social Mindscapes. An Invitation to Cognitive Sociology, Cambridge, MA, Harvard University Press.

Pedro Abrantes. Professor da Universidade Aberta e investigador do Centro de Investigação e Estudos de Sociologia (CIES-IUL), Av. das Forças Armadas, 1649-026 Lisboa, Portugal. E-mail: pedro.abrantes@iscte.pt

Receção: 06-03-2015

Aprovação: 20-11-2015 
